Document downloaded from:

http://hdl.handle.net/10251/103301

This paper must be cited as:

Argente, MJ.; Calle, EW.; Garcia, ML.; Blasco Mateu, A. (2017). Correlated response in litter size components in rabbits selected for litter size variability. Journal of Animal Breeding and Genetics. 134(6):505-511. doi:10.1111/jbg.12283

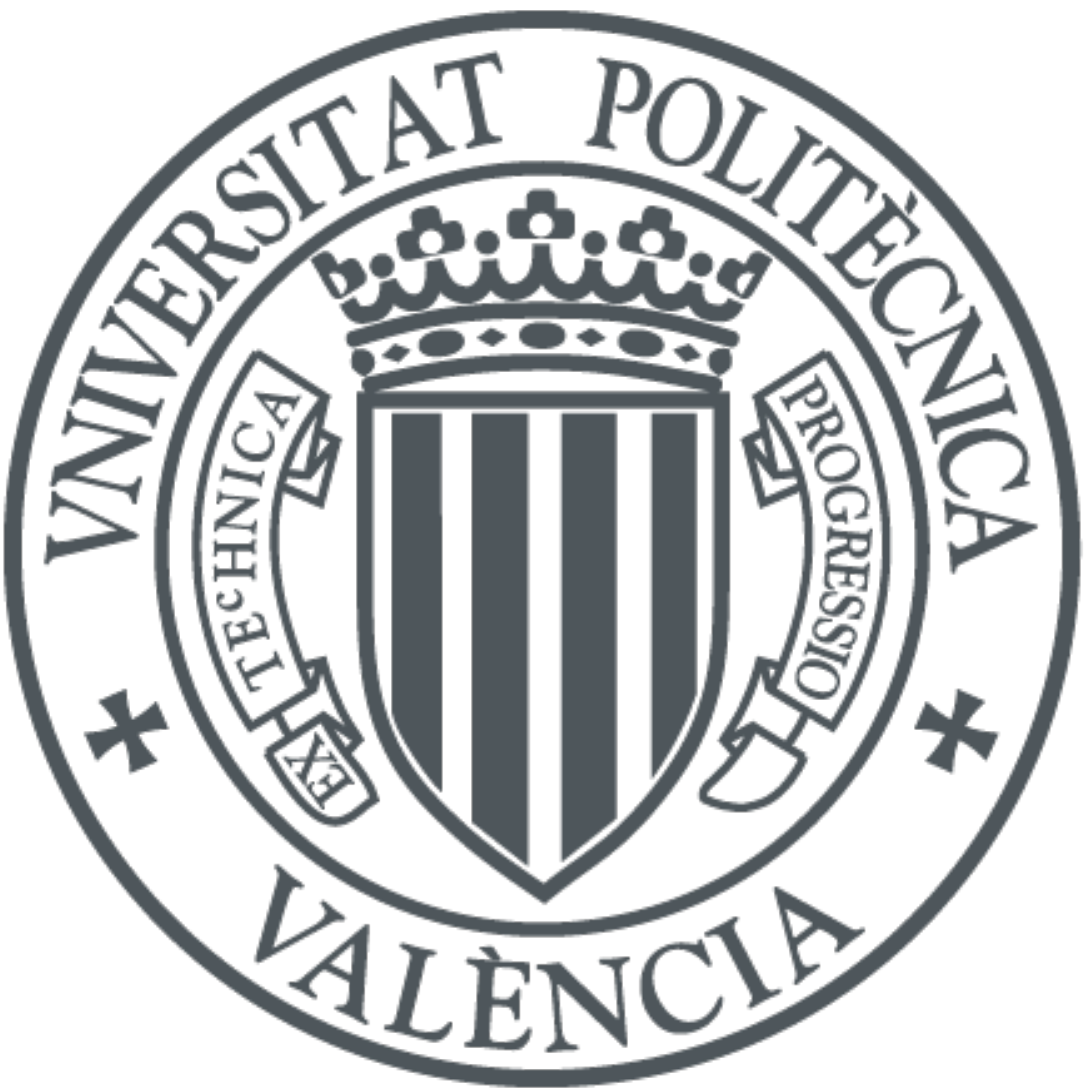

The final publication is available at

https://doi.org/10.1111/jbg.12283

Copyright Blackwell Publishing

Additional Information 


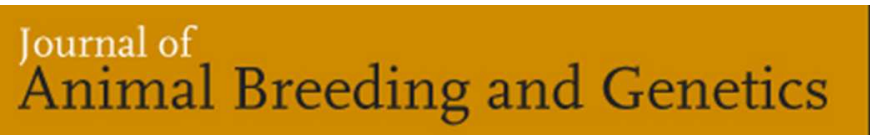

\section{CORRELATED RESPONSE IN LITTER SIZE COMPONENTS IN RABBITS SELECTED FOR LITTER SIZE VARIABILITY}

\begin{tabular}{|r|l|}
\hline Journal: & Journal of Animal Breeding and Genetics \\
\hline Manuscript ID & Draft \\
\hline Manuscript Type: & Original Article \\
\hline Date Submitted by the Author: & n/a \\
\hline Complete List of Authors: & $\begin{array}{l}\text { Argente, Maria-Jose; Universidad Miguel Hernandez de Elche, } \\
\text { Departamento de Tecnología Agroalimentaria } \\
\text { Calle, Eddy; Universitat Politecnica de Valencia, Institute for Animal } \\
\text { Science and Technology } \\
\text { García, M. Luz; Universidad Miguel Hernández de Elche, tecnologia } \\
\text { Agroalimentaria } \\
\text { BLASCO, AGUSTIN }\end{array}$ \\
\hline Subject Area: & animal breeding, correlation, estimation, heritability, selection \\
\hline & \\
\hline
\end{tabular}

SCHOLARONE ${ }^{m}$

Manuscripts 

SELECTED FOR LITTER SIZE VARIABILITY

3

4

M.J. Argente ${ }^{1 *}$, E.W. Calle ${ }^{2}$, M.L. García ${ }^{1}$, A. Blasco ${ }^{2}$

5

$6{ }^{1}$ Departamento de Tecnología Agroalimentaria. Universidad Miguel Hernández de Elche,

7 Ctra de Beniel Km 3.2, 03312 Orihuela, Spain.

8

$9 \quad{ }^{2}$ Institute for Animal Science and Technology. Universitat Politècnica de València, P.O. Box

10 22012. 46022 Valencia, Spain.

11

12 *Corresponding author: M.J. Argente. e-mail: mj.argente@umh.es

13

14 Short title: Correlated Responses in litter size components 


\section{Summary}

17 A divergent selection experiment for litter size environmental variability has been carried out

18 in rabbits at the University Miguel Hernández of Elche in Spain over seven generations.

19 Environmental variability of litter size was estimated as phenotypic variance within female 20 after correcting for year-season and parity-lactation status. The aim of this study was to 21 analyse the correlated responses to selection in litter size components. Ovulation rate (OR) 22 and number of implanted embryos (IE) were measured by laparoscopy at $12 \mathrm{~d}$ of the second 23 gestation in females. At the end of the second gestation, litter size was measured as total 24 number of kits born at second parity (TB). Embryonic (ES), fetal (FS) and prenatal (PS) 25 survival were estimated as $\mathrm{IE} / \mathrm{OR}, \mathrm{TB} / \mathrm{IE}$ and $\mathrm{TB} / \mathrm{OR}$, respectively. A total of 405 26 laparoscopies were performed. Data were analysed using Bayesian methodology. Correlated 27 response to selection for litter size environmental variability in litter size components was 28 estimated either as genetic trends from the estimated genetic means and as phenotypic 29 differences between lines. Ovulation rate was similar in both lines. However, after seven 30 generations of selection, the line selected for homogeneity in litter size showed more embryos 31 at implantation (1.09 embryos for genetic means and 1.23 embryos for phenotypic means, $\mathrm{P}=$ 32 1.00) and higher embryonic survival than the heterogeneous one (0.07 for genetic means and 330.08 for phenotypic means, $\mathrm{P}=0.99$ ). A higher uterine overcrowding of embryos in the 34 homogeneous line did not penalise fetal survival, and as a result, this line continued showing 35 a greater number of kits born at birth (1.01 kits for genetic means and 1.30 kits for phenotypic 36 means, $\mathrm{P}=0.99$, in the seventh generation of selection). In conclusion, a decrease in litter size 37 variability showed a favourable effect on embryonic survival leading to a higher litter size at 38 birth.

39 Keywords: implanted embryos, litter size, ovulation rate, rabbit, residual variance. 


\section{Introduction}

42 Interest in the genetic determination of environmental variance is increasing, since the 43 livestock industry is demanding a more homogeneous production (Mulder et al. 2008); for 44 example, increasing uniformity in litters can help management and increase litter viability. On 45 the other hand, a decrease in environmental variance will increase the heritability, being 46 particularly interesting for increasing the response to selection in low heritability traits, such 47 as litter size (Argente et al. 2010; Formoso-Rafferty et al. 2016). A direct divergent selection experiment for litter size environmental variance is currently being carried out in rabbits. The experiment has had success, showing a difference for litter size variability of $30 \%$ between the divergent lines (Blasco et al. 2017). Litter size environmental variance is related to litter 51 size, but the sign of this relationship is controversial. In pigs' litter size and in rabbits' uterine 52 capacity, Yang et al. (2011) found that, after the Box-Cox transformation, the relationship 53 between mean and environmental variance changed from negative to positive. Hence, it will 54 be interesting to learn how this selection process is affecting litter size, and also at which 55 gestation moment the selection process is acting. The objective of this study is to analyse the 56 correlated responses to selection for litter size environmental variability in litter size 57 components.

\section{Materials and Methods}

\section{Animals}

60 A divergent selection experiment for litter size environmental variability has been carried out 61 in rabbits during seven generations. Each divergent line had approximately 125 females and 25 62 males per generation. Selection was based on phenotypic variance of litter size within female 
63 after correcting litter size for year-season and parity-lactation status (first parity, and lactating

64 or not at mating in other parities). As all litters have almost the same genetic determination 65 (Piles et al. 2006) and the same environmental permanent effects, after correcting for 66 systematic effects, the phenotypic variance intra-doe is a record of its residual variance (Ve).

67 The selection pressure on females was approximately $20 \%$ in each line. Males were chosen 68 within sire families in order to avoid an increase of inbreeding. All animals were kept on a 69 farm at the Miguel Hernández University of Elche (Spain). Rabbits were fed a standard 70 commercial diet (218 $\mathrm{g}$ acid detergent fibre and $174 \mathrm{~g}$ crude protein per $\mathrm{kg}$ of dry matter; 71 Cunilactal, Nutreco). Food and water were provided ad libitum. Females were kept in 72 individual cages under a constant photoperiod of $16 \mathrm{~h}$ continuous light: $8 \mathrm{~h}$ continuous 73 darkness and controlled ventilation. They were first mated at $18 \mathrm{wk}$ of age and at $10 \mathrm{~d}$ after 74 parturition thereafter. Litters were not standardised. All experimental procedures involving 75 animals were approved by the Miguel Hernández University of Elche Research Ethics 76 Committee (Reference number DTA-MJA-001-11), in accordance with Council Directives 77 98/58/EC and 2010/63/EU.

78 Traits

79 Ovulation rate (OR), estimated as the number of corpora lutea in both ovaries, and the number 80 of implanted embryos (IE), estimated as the number of implantation sites, were measured by 81 using laparoscopy at d 12 of second gestation in females from $6^{\text {th }}$ and $7^{\text {th }}$ generations of 82 selection. The laparoscopy technique is described in detail by Argente et al. (2003). At the 83 end of the second gestation, litter size was measured as total number of kits born at second 84 parity (TB). Embryonic survival (ES) was estimated as IE/OR, fetal survival (FS) was 85 estimated as TB/IE, and prenatal survival (PS) was estimated as TB/OR.

86 Data from 405 laparoscopies and litter size at second parity were analysed. There were 2,082 
87 records for litter size residual variance. The total number of animals in the pedigree was $882,775$.

\section{Statistical Analyses}

90 Correlated response in litter size at second parity and its components was estimated as 91 differences between lines in $6^{\text {th }}$ and $7^{\text {th }}$ generation. The differences between lines were 92 analysed using a liner model with effects of line-generation, lactation status at mating 93 (lactating or non-lactating) and year-season.

94 Correlated response to selection was also estimated as the average of the genetic values in 95 each generation. Bivariate animal models were fitted in order to estimate the genetic 96 parameters and genetic responses. All analysis included selection trait, litter size residual 97 variance. The model for litter size residual variance included generation as fixed and genetic 98 value as random effect. For the rest of traits, the model considered fixed effects of lactation 99 status at mating (lactating or non-lactating at mating) and year-season, and random effect of 100 genetic value.

101 For the bivariate model, the traits were assumed to be conditionally normally distributed as 102 follows:

$$
\left[\begin{array}{l}
y_{1} \\
y_{2}
\end{array}\right] \mid \mathbf{b}_{1}, \mathbf{b}_{2}, \mathbf{a}_{1}, \mathbf{a}_{2}, \mathbf{R} \sim \mathbf{N}\left(\mathbf{X}\left[\begin{array}{l}
b_{1} \\
b_{2}
\end{array}\right]+\mathbf{Z}\left[\begin{array}{l}
a_{1} \\
a_{2}
\end{array}\right], \mathbf{R}\right)
$$

103 Where $\mathbf{b}_{1}$ and $\mathbf{b}_{\mathbf{2}}$ are random vectors including the effects of generation, lactation status at 104 mating and year-season, $\mathbf{a}_{1}$ and $\mathbf{a}_{2}$ are vectors of individual additive genetic effects, $\mathbf{X}$, and $\mathbf{Z}$ 105 are known incidence matrices, and $\mathbf{R}$ is the residual (co)variance matrix. Between individuals, 106 only the additive random effects are assumed correlated. Between traits, the additive, and the 107 residual effects are assumed correlated. The residual (co)variance matrix can be written as $\mathbf{R}_{\mathbf{0}}$ 
$108 \otimes \mathbf{I}_{\mathbf{n}}$ with $\mathbf{R}_{\mathbf{0}}$ being the $2 \times 2$ residual (co)variance matrix between the traits analysed and $\mathbf{I}_{\mathbf{n}}$

109 an identity matrix of appropriate order. Bounded uniform priors were used to represent vague

110 previous knowledge of distributions of $\mathbf{b}_{\mathbf{1}}$ and $\mathbf{b}_{\mathbf{2}}$. Prior knowledge concerning additive effect

111 was represented by assuming that they were normally distributed, conditionally on the

112 associated (co)variance components, as follows:

$$
\left[\begin{array}{l}
a_{1} \\
a_{2}
\end{array}\right] \mid \mathbf{G} \sim \mathbf{N}(\mathbf{0}, \mathbf{G})
$$

113 Where $\mathbf{0}$ is a vector of zeros, and $\mathbf{G}$ is the genetic (co)variance matrix. The matrix $\mathbf{G}$ could be

114 written as $\mathbf{G}_{\mathbf{0}} \otimes \mathbf{A}$, in which $\mathbf{G}_{\mathbf{0}}$ is the $2 \times 2$ genetic and $\mathbf{A}$ is the known additive genetic

115 relationship matrix. Bounded uniform priors were used for the components of the

116 (co)variance matrices $\mathbf{R}_{\mathbf{0}}$ and $\mathbf{G}_{\mathbf{0}}$.

117 Bayesian analyses were performed, with bounded flat priors for all unknowns. Features of the

118 marginal posterior distributions were estimated using Gibbs sampling. For the differences

119 between lines, after some exploratory analyses, we used a chain of 60,000 samples, with a

120 burn-in period of 10,000 , only one of every 10 samples saved for inferences. The Rabbit

121 program developed by the Institute for Animal Science and Technology (Valencia, Spain)

122 was used for these procedures. For the genetic analyses, we used a chain of $1,000,000$

123 samples, and burn-in of 500,000; only one of every 100 samples saved for inferences. The

124 program TM developed by Legarra et al. (2008) was used for these procedures. Convergence

125 was tested using the $\mathrm{Z}$ criterion of Geweke (Sorensen and Gianola 2002).

\section{Results and Discussion}

127 Genetic and phenotypic parameters

128 For all the traits analysed, Monte Carlo SE were small. The Geweke test did not detect lack of 
129 convergence in any case. Mean and median are similar for all the traits showing that, in all

130 cases, the marginal posterior distributions were symmetric, and therefore only median values

131 are given in the tables.

132 The features of the estimated marginal posterior distributions of heritabilities for the traits are 133 summarized in Table 1. Estimates of heritabilities were moderate for OR, IE and ES (0.33, 1340.26 , and 0.25 , respectively), with a probability of $100 \%$ for OR, $97 \%$ for IE and $98 \%$ for ES 135 of being at least 0.10 . The litter size at second parity had a low heritability ( 0.13 for TB), 136 being similar to the heritabilities of FS and PS (0.09 in both traits). Heritability was higher in 137 the traits that determinate the success of pregnancy at the early stages than in those are acting 138 at the end stages. The estimated heritabilities for OR, IE, ES, FS, PS and TB were within the 139 value range reported by other studies in rabbits (Blasco et al. 1993; Argente et al. 2000;

140 Garreau et al. 2004; Ibañez et al. 2006; Ziadi et al. 2013) and in pigs (Johnson et al. 1999;

141 Ruiz-Flores and Johnson, 2001; Rosendo et al. 2007).

142 The features of the estimated marginal posterior distributions of the genetic correlations are 143 shown in Table 2. In general, genetic correlations were estimated with large HPD $95 \%$ (Table 144 2). To obtain genetic parameters with greater precision, a larger set of data would be needed. 145 However, the nature of these kinds of experiments, which require techniques including 146 laparoscopy or slaughter, prevents the collection of large data sets. For this reason, we can 147 often only draw conclusions about the sign of these genetic correlations. In accordance with 148 that, the posterior medians of the genetic correlation between the selection criterion (Ve) with 149 IE, ES, PS and TB showed large $\mathrm{HPD}_{95 \%}$ (Table 2), but all them were negative with a high 150 probability (P was always higher than $90 \%$, Table 2 ). Genetic correlations between Ve with 151 both OR and FS exhibited greater imprecision, as we can see in their large credibility 152 intervals. Their P does not allow to infer about their signs. 
153 The features of the estimated marginal posterior distributions of the phenotypic correlations

154 are also summarized in Table 2. Generally, phenotypic correlations showed the same sign that

155 their genetics correlation, but with a higher accuracy, except for IE (see HPD $95 \%$, Table 2). All

156 traits exhibited a low negative phenotypic correlation with the selection criterion (Ve), with

157 the exception of OR, that had a positive phenotypic correlation although it was low. Selection

158 for environmental variance has been proposed under complex models (San Cristobal et al.

159 1998), which robustness and effectiveness have been questioned (Sorensen, 2010). In this

160 regard, Yang et al. (2011) showed that small deviations from normality in the residuals can

161 substantially change the genetic parameters estimated, finding that the coefficient of

162 correlation between the trait and its variability changed the sign in the case of pigs litter size

163 after a Box-Cox transformation for normalizing the residuals. To avoid the possible

164 mathematical artefacts of complex models, we have performed a divergent selection

165 experiment in rabbits directly on environmental variance with success (Blasco et al. 2017).

166 This is the first time that environmental variance is treated as an observed trait, and it is

167 examined the consequences that this selection process had on litter size components. Our

168 results showed a negative correlation between litter size variability with number of implanted

169 embryos and with litter size. This is in agreement with Ibáñez-Escriche et al. (2008), who

170 reported a negative correlation between uterine capacity and its residual variability in rabbits, a

171 trait highly correlated with litter size (Argente et al. 2000).

\section{Correlated response to selection}

173 Table 3 shows phenotypic differences between the high and low lines for all traits in the sixth

174 and seventh generation of selection. Ovulation rate was similar in both lines in the last two

175 generations of selection. For the number of implanted embryos, the low line had 0.61 more

176 embryos at implantation $(\mathrm{P}=0.93)$ and a higher embryonic survival than the high line $(0.04, \mathrm{P}$ 
$177=0.92)$ in the sixth generation of selection. These differences were greater in the seventh

178 generation of selection (1.23 for number of implanted embryos, $\mathrm{P}=1.00$; and 0.08 for

179 embryonic survival, $\mathrm{P}=0.99$ ). In a Bayesian context, several confidence intervals can be easily

180 estimated. We can provide intervals $[\mathrm{k},+\infty)$, where $\mathrm{k}$ can be interpreted as a guaranteed value

181 with a determined probability (Blasco, 2005). The guaranteed value at $80 \%$ probability was

1820.83 for number of implanted embryos and 0.05 for embryonic survival in the seventh

183 generation of selection; this means that the correlated response in these traits has been at least

1840.83 and 0.05 , respectively, with $80 \%$ probability. Fetal survival was also greater in the low

185 line than in the high line $(0.06, \mathrm{P}=0.95$ in the sixth generation; $0.04, \mathrm{P}=0.86$ in the seventh

186 generation). Moreover, litter size at second parity was also consistently higher in the low line

187 than in the high line. In the seventh generation of selection, the difference in litter size

188 between the low and high lines was 1.30 kits $(\mathrm{P}=0.99)$, with a guaranteed value of 0.85 kits

189 with $80 \%$ probability.

190 The Figure 1 and 2 show the evolution of the genetic trends for litter size at second parity and

191 its components in the high and low lines. Except for OR, the lines increased divergences in

192 the remaining traits when selection process advanced. We note that, in the last generation of

193 selection, the differences in genetic means between lines showed similar values to the

194 phenotypic differences in all analysed traits $(0.11$ ova in OR, 1.09 embryos in IE, 1.01 kits in

$195 \mathrm{~TB}, 0.07$ in ES, 0.03 in FS and 0.06 in PS). The correlated response to selection can be

196 estimated as phenotypic differences between lines and as genetic trends from the estimated

197 genetic means. All methods based in genetic trends (BLUP-REML or Bayesian methods) are

198 model-dependent and the genetic trends directly depend on the genetic parameters used

199 (Thompson, 1986; Sorensen and Johansson, 1992). The advantage of the simple difference

200 between high and low lines is that they are independent of any model; whether there are major

201 genes, dominance or other effects. We reported in this study that the phenotypic differences 
202 are coincident with the estimates based in a genetic model. Therefore this would corroborate

203 the model used.

204 Homogeneity is an economically important trait in livestock production (Mulder et al. 2008).

205 In the case of litter size, a reduction in environmental variability can be related to better

206 adaptation of the animal to environmental changes, and in consequence, with an improvement

207 in welfare to the animal. After seven generations of selection, we report that selection for litter

208 size variability has a negative correlated response with litter size. Our results show that the

209 difference in litter size between lines was established at implantation. There is evidence that

210 maternal stress around the time of implantation increases the failure rate in blastocyst

211 implantation (Burkuš et al. 2015). We hypothesise that the line selected for heterogeneity in litter

212 size should be more sensitive to stress and diseases than the homogeneous line. In this regard,

213 Argente et al. (2014) found a lower immune response to pathogenic agents in females from the

214 heterogeneous line, showing greater sensitivity to diseases. This would be in agreement with a

215 larger number of embryonic losses around implantation in this line.

216 In conclusion, selection for litter size variability showed a negative correlated response in 217 embryonic survival, which continued at birth for litter size.

\section{Acknowledgments}

219 This study was financed by the Spanish Ministry of Economy and Competitiveness 220 (MINECO) (Grant no. AGL2011-29831-C03-02 and AGL2014-55921-C2-2-P). Eddy W.

221 Calle was supported by a research grant within the Babel project from the Erasmus Mundus 222 programme.

\section{References}


224 Argente, M.J., Santacreu, M.A., Climent, A., Blasco, A. (2000). Genetic correlations between 225 litter size and uterine capacity. In Proceeding of the 8th World Rabbit Congress. Valencia 226 227 228 (Spain), 4-7 July 2000, pp 333-338.

Argente, M.J., Blasco, A.; Ortega, J.A., Haley, C.S., Visscher, P.M. (2003) Analyses for the presence of a major gene affecting uterine capacity in unilaterally ovariectomized rabbits. Genetics, 163(3), 1061-1068.

Argente, M.J., Garcia, M.L., Muelas, R., Santacreu, M.A., Blasco, A. (2010). Preliminary results in a divergent selection experiment on variance for litter size in rabbits. In Proceedings of the 9th World Congress on Genetics Applied to Livestock Production. Leipzig (Germany), 1-6 August 2010, Communication 0526.

Argente, M.J., García, M.L., Zbynovska, K., Petrusca, P., Capcarova, M., Blasco, A. (2014). Effect of selection for residual variance of litter size on haematology parameters as immunology indicators in rabbits. In Proceedings of 10th World Congress on Genetics Applied to Livestock Production. Vancouver (Canada), 17-22 August 2014, Communication 631 .

Blasco, A., Santacreu, M.A., Thompson, R., Haley, C. (1993). Estimates of genetic parameters for ovulation rate, prenatal survival and litter size in rabbits from an elliptical selection experiment. Livestock. Prod. Sci. 34: 163-174.

Blasco A. (2005). The use of Bayesian statistics in meat quality analyses. Meat Sci. 69:15 122.

Blasco, A., Martínez-Álvarado, M., García, M.L., Ibáñez-Escriche, N., Argente, M.J. (2017). Selection for genetic environmental sensitivity of litter size in rabbits. Gen. Sel. Evol. Accepted to publication. 
247 Burkuš, J., Kačmarová, M., Kubandová, J.: Kokošová, N., Fabianová, K.: Fabian, D., Koppel,

248 J., Čikoš Š. (2015). Stress exposure during the preimplantation period affects blastocyst 249 lineages and offspring development. J. Reprod. Develop. 61(4): 325-331.

250 Formoso-Rafferty, N., Cervantes, I., Ibáñez-Escriche, N., Gutiérrez, J.P. (2016). Modulación

251 de la heredabilidad del peso al nacimiento en ratones. In Proceeding of the XVIII

252 Reunión Nacional de Mejora Genética Animal. Valencia (Spain), 2-3 Junio 2016, $253 \quad$ Communication 22.

254 Garreau, H., Piles, M., Larzul, C., Baselga, M., Rochambeau, H. (2004). Selection of maternal 255 lines: Last results and prospects. In Proceeding of 8th World Rabbit Congress. Puebla 256 (México), 7-10 September 2004, pp 14-25.

257 Ibáñez, N., Santacreu, M.A., Martínez, M., Climent, A., Blasco, A. (2006). Selection for 258 ovulation rate in rabbits. Livest. Sci. 101: 126-133.

259 Ibáñez-Escriche, N., Sorensen, D., Waagepetersen, R., Blasco, A. (2008). Selection for 260 environmental variation: a statistical analysis and power calculations to detect response. $261 \quad$ Genetics. 180(4): 2209-2226.

262 Johnson, R. K., Nielsen, M.K., Casey, D.S. (1999). Responses in ovulation rate, embryonal 263 survival and litter traits in swine to 14 generations of selection to increase litter size. $J$. 264 Anim. Sci. 77:541-557

265 Legarra, A., Varona, L., López de Maturana, E. (2008). Program TM. 266 http://snp.toulouse.inra.fr/ alegarra/. Accessed September 17, 2016

267 Mulder, H.A., Bijma, P., Hill, W.G. (2008). Selection for uniformity in livestock by 268 exploiting genetic heterogeneity of residual variance. Gen. Sel. Evol. 40(1): 37-59.

269 Piles M., García M.L., Rafel O., Ramon J., Baselga M. (2006). Genetics of litter size in three 270 maternal lines of rabbits: Repeatability versus multiple-trait models. J. Anim. Sci. 
84:2309-2315.

272 Rosendo, A., Druet, T., Gogue, J., Bidanel, J.P. (2007). Direct responses to six generations of 273 selection for ovulation rate or prenatal survival in Large White pigs. J. Anim. Sci. 85:356$274 \quad 364$.

275 Ruiz-Flores, A., Johnson, R.K. (2001). Direct and correlated responses to two-stage selection 276 for ovulation rate and number of fully formed pigs at birth in swine. J. Anim. Sci. $277 \quad 79: 2286-2299$

278 San Cristobal, M., Elsen, J.M., Bodin, L., Chevalet, C. (1998). Prediction of the response to a 279 selection for canalisation of a continuous trait in animal breeding. Genet. Sel. Evol. 30: $280 \quad 423-451$.

281 Sorensen, D.A., Johansson, K. (1992). Estimation of direct and correlated responses to 282 selection using univariate animal models. J. Anim. Sci. 70: 2038-2044.

283 Sorensen, D. (2010). The Genetics of Environmental Variation. In Proceeding of 9th World 284 Congress on Genetics Applied to Livestock Production. Leipzig (Germany), 1-6 Augoust 285 2010. paper 72.

286 Sorensen, D., Gianola, D. (2002). Likelihood, bayesian, and MCMC Methods in quantitative 287 genetics. Springer Science and Business Media

288 Thompson, R. (1986). Estimation of realized heritability in a selected population using mixed 289 model methods. Gen. Sel. Evol. 18:475-484.

290 Yang Y., Christensen, O.F., Sorensen, D. (2011). Analysis of a genetically structured variance 291 heterogeneity model using the box-cox transformation. Genet. Res. 93: 33-46. 
292 Ziadi, C., Mocé, M.L., Laborda, P., Blasco, A., Santacreu, M.A. (2013). Genetic selection for 293 ovulation rate and litter size in rabbits: Estimation of genetic parameters and direct and 294 correlated responses. J Anim Sci. 91(7): 3113-3120.

295 
296 Table 1. Features of the marginal posterior distributions of heritability for ovulation rate (OR),

297 number of implanted embryos (IE), total number of kits born at second parturition (TB),

298 embryonic survival (ES), fetal survival (FS) and prenatal survival (PS).

\begin{tabular}{lllll}
\hline Trait & median & $\mathrm{HPD}_{95 \%}$ & $\mathrm{P}_{0.10}$ & $\mathrm{k}_{80 \%}$ \\
\hline OR & 0.33 & $0.15,0.56$ & 1.00 & 0.24 \\
IE & 0.26 & $0.08,0.46$ & 0.97 & 0.17 \\
ES & 0.25 & $0.09,0.45$ & 0.98 & 0.18 \\
FS & 0.09 & $0.01,0.24$ & 0.48 & 0.05 \\
PS & 0.09 & $0.02,0.24$ & 0.47 & 0.06 \\
TB & 0.13 & $0.02,0,29$ & 0.67 & 0.08
\end{tabular}

$299 \mathrm{HPD}_{95 \%}$ : high posterior density interval at 95\%. $\mathrm{P}_{0.10 \text { : }}$ probability of the heritability being

300 higher than $0.10 . \mathrm{k}_{80 \%}$ : limit for the interval $[\mathrm{k},+\infty)$ having a probability of $80 \%$. 
302 Table 2. Features of the posterior distributions of genetic and phenotypic correlation.

\begin{tabular}{|c|c|c|c|c|c|c|c|c|}
\hline & Genetic & orrelation & & & Phenotyp & ic correlation & & \\
\hline Trait & Median & $\mathrm{HPD}_{95 \%}$ & $\mathrm{P}$ & $\mathrm{k}_{80 \%}$ & Median & $\mathrm{HPD}_{95 \%}$ & $\mathrm{P}$ & $\mathrm{k}_{80 \%}$ \\
\hline Ve, OR & -0.08 & $-0.65,0.49$ & $0.61^{b}$ & 0.17 & 0.15 & $0.07,0.24$ & $1.00^{\mathrm{a}}$ & 0.11 \\
\hline Ve, IE & -0.49 & $-0.97,0.08$ & $0.92^{\mathrm{b}}$ & -0.20 & -0.04 & $-0.12,0.05$ & $0.71^{\mathrm{b}}$ & -0.02 \\
\hline Ve, ES & -0.43 & $-0.97,0.11$ & $0.91^{\mathrm{b}}$ & -0.15 & -0.08 & $-0.17,0.01$ & $0.97^{\mathrm{b}}$ & -0.04 \\
\hline Ve, FS & -0.18 & $-0.99,0.63$ & $0.65^{\mathrm{b}}$ & 0.17 & -0.27 & $-0.36,-0.19$ & $1.00^{\mathrm{b}}$ & -0.24 \\
\hline $\mathrm{Ve}, \mathrm{PS}$ & -0.54 & $-0.99,0.08$ & $0.93^{\mathrm{b}}$ & -0.21 & -0.27 & $-0.35,-0.19$ & $1.00^{\mathrm{b}}$ & -0.24 \\
\hline $\mathrm{Ve}, \mathrm{TB}$ & -0.45 & $-0.99,0.16$ & $0.90^{\mathrm{b}}$ & -0.77 & -0.19 & $-0.28,-0.11$ & $1.00^{\mathrm{b}}$ & -0.16 \\
\hline \multicolumn{9}{|c|}{$\begin{array}{l}\mathrm{HPD}_{95 \%} \text { : high posterior density interval at } 95 \% \text {. P: probability of the genetic correlation being } \\
\text { greater than } 0 \text { (superscript a) or less than } 0 \text { (superscript b).k } \mathrm{k}_{80 \%} \text { : limit for the interval }{ }^{\mathrm{a}}[\mathrm{k}+1),{ }^{\mathrm{b}} \\
(-1, \mathrm{k}] \text {, having a probability of } 80 \% \text {. Ve: residual variance of litter size. OR: ovulation rate. }\end{array}$} \\
\hline \multicolumn{9}{|c|}{ IE: number of implanted embryos. ES: embryonic survival. FS: fetal survival. PS: prenatal } \\
\hline
\end{tabular}

307 survival. TB: total number of kits born at second parturition. 
308 Table 3. Correlated response. Features of the estimated marginal posterior distribution of the

309 differences between the high and low lines in the sixth (G6) and the seventh (G7) generation

310 of selection.

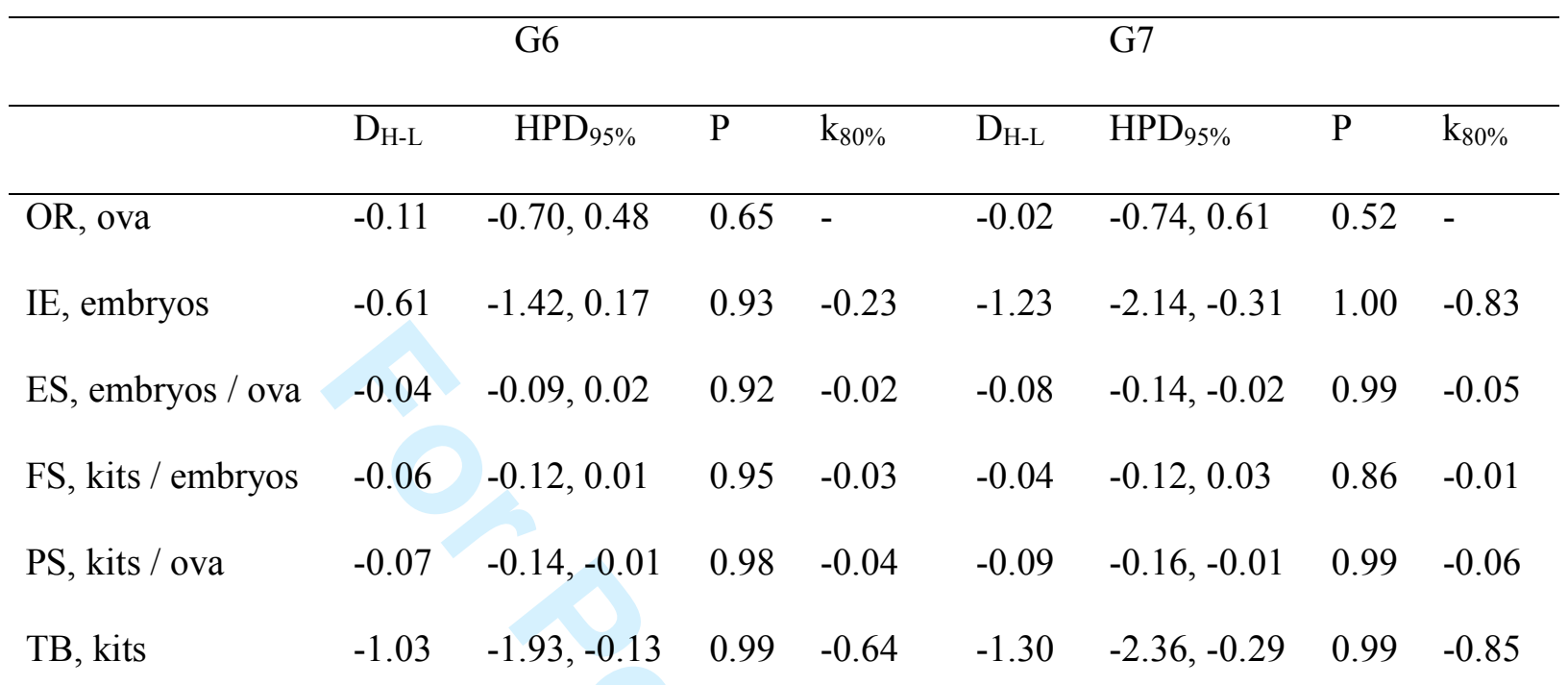

$311 \mathrm{D}_{\mathrm{H}-\mathrm{L}}$ : median of the difference between the High and Low lines. HPD ${ }_{95 \%}$ : highest posterior

312 density region at $95 \%$. P: probability of the difference being $>0$ when $\mathrm{D}_{\mathrm{H}-\mathrm{L}}>0$ and probability

313 of the difference being $<0$ when $\mathrm{D}_{\mathrm{H}-\mathrm{L}}<0$. $\mathrm{k}_{80 \%}$ : limit of the interval $[\mathrm{k},+\infty)$ when $\mathrm{D}_{\mathrm{H}-\mathrm{L}}>0$ and

$314(-\infty, \mathrm{k}]$ when $\mathrm{D}_{\mathrm{H}-\mathrm{L}}<0$ at $80 \%$ of probability. It is displayed in the table only when $\mathrm{D}_{\mathrm{H}-\mathrm{L}}$ and

$315 \mathrm{k}_{80 \%}$ have the same sign. OR: ovulation rate. IE: number of implanted embryos. ES:

316 embryonic survival. FS: fetal survival. PS: prenatal survival. TB: total number of kits born at

317 second parturition. 
319 Figure 1. Correlated response to selection in the High and Low lines. 1. a) Genetic means per

320 generation for ovulation rate at second gestation. 1. b) Genetic means per generation for

321 number of implanted embryos at second gestation. 1. c) Genetic means per generation for 322 total number of kits born at second parturition.

323 
1

2

3

4

5

6

7

8

9

10

11

12

13

14

15

16

17

18

19

20

21

22

23

24

25

26

27

28

29

30

31

32

33

34

35

36

37

38

39

40

41

42

43

44

45

46

47

48

49

50

51

52

53

54

55

56

57

58

59

60
324 Figure 2. Correlated response to selection in the High and Low lines. 2.a) Genetic means per 325 generation for embryo survival at second gestation. 2.b) Genetic means per generation for 326 fetal survival at second gestation. 2.c) Genetic means per generation for prenatal survival at 327 second gestation. 


1
2
3
4
5
6
7
8
9
10
11
12
13
14
15
16
17
18
19
20
21
22
23
24
25
26
27
28
29
30
31
32
33
34
35
36
37
38
39
40
41
42
43
44
45
46
47
48
49
50
51
52
53
54
55
56
57
58
60

1

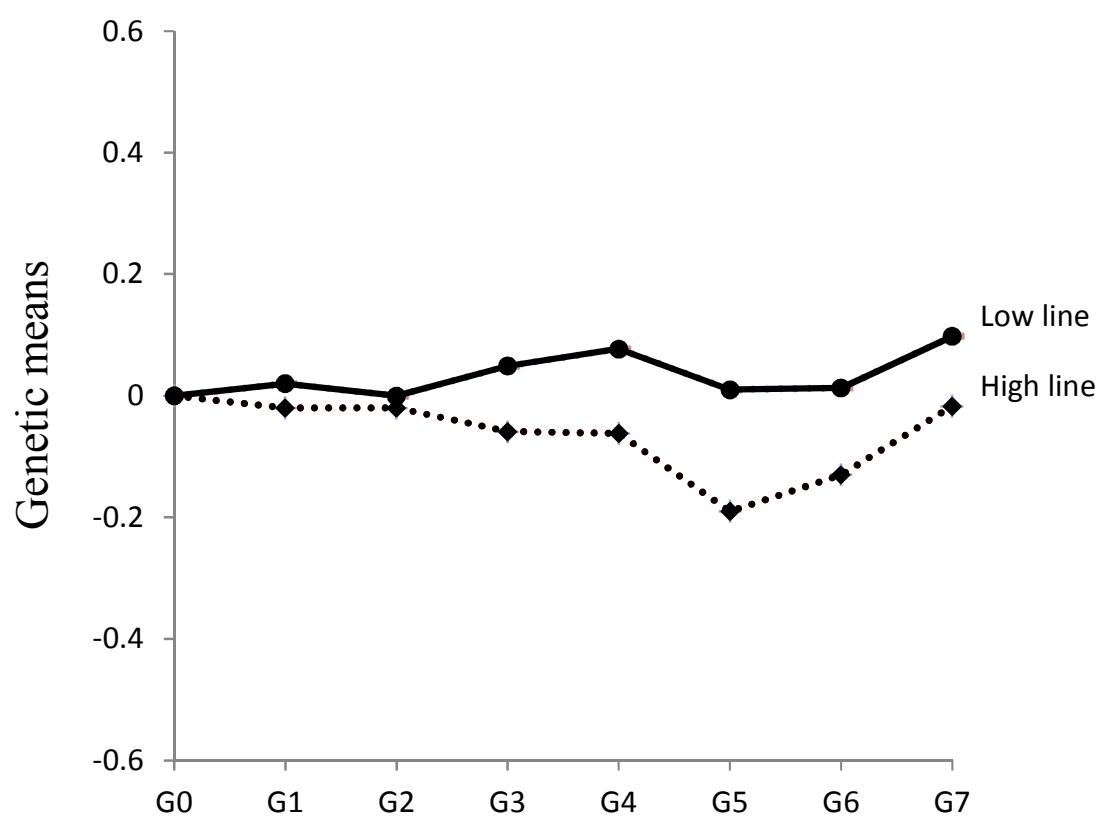

2

1. a) Correlated response to selection in ovulation rate 


1
2
3
4
5
6
7
8
9
10
11
12
13
14
15
16
17
18
19
20
21
22
23
24
25
26
27
28
29
30
31
32
33
34
35
36
37
38
39
40
41
42
43
40
45
49
50
51
52
53
55
50

5

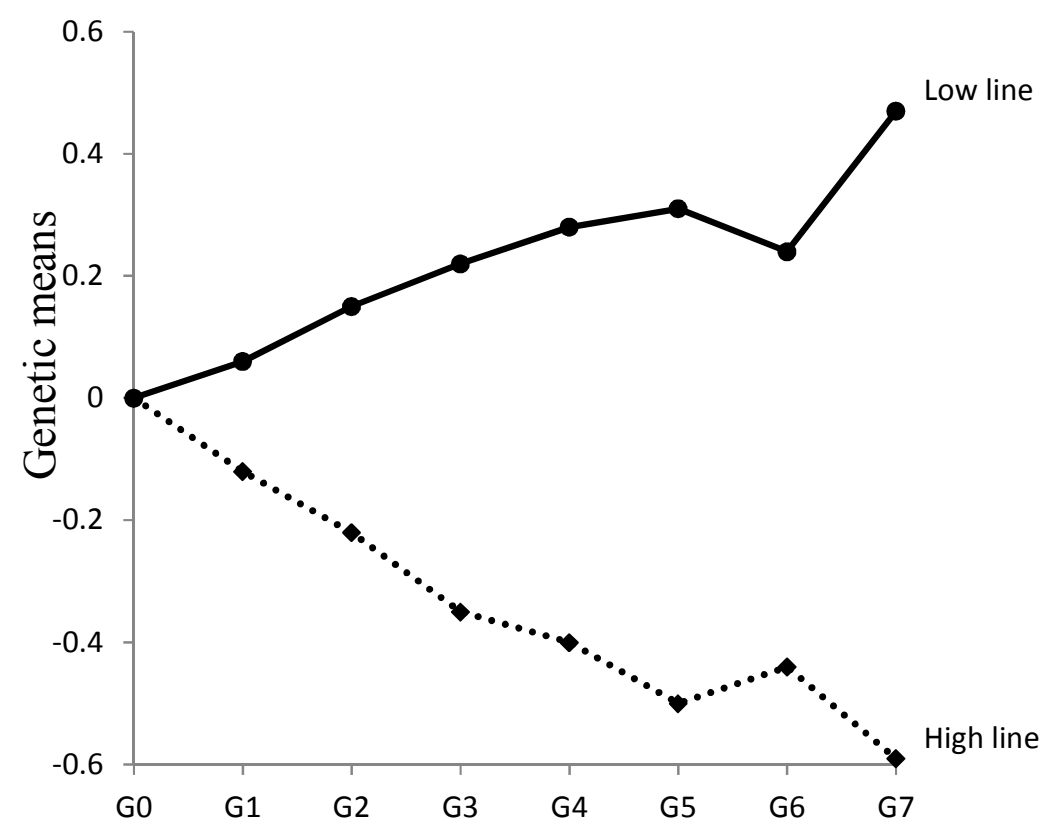

1. b) Correlated response to selection in number of implanted embryos 
9

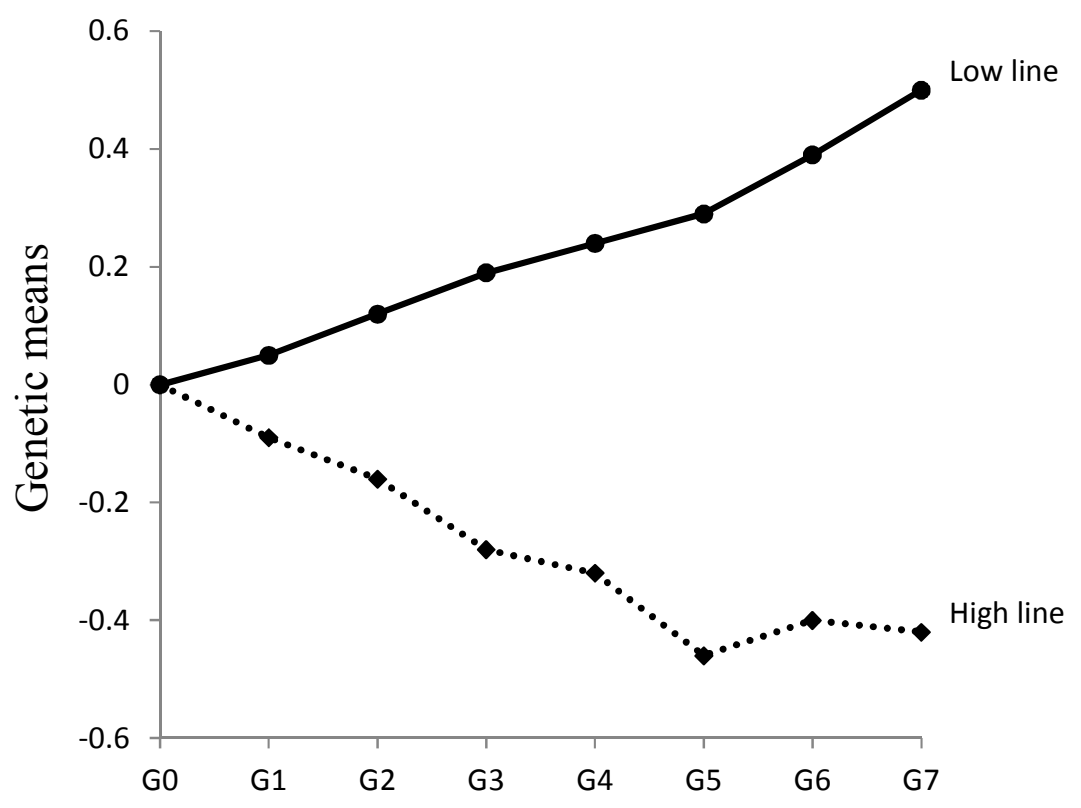

1. c) Correlated response to selection in litter size 
1

2

3

4

5

6

7

8

9

10

11

12

13

14

15

16

17

18

19

20

21

22

23

24

25

26

27

28

29

30

31

32

33

34

35

36

37

38

39

40

41

42

43

44

45

46

47

48

49

50

51

52

53

54

55

56

57

58

59

60

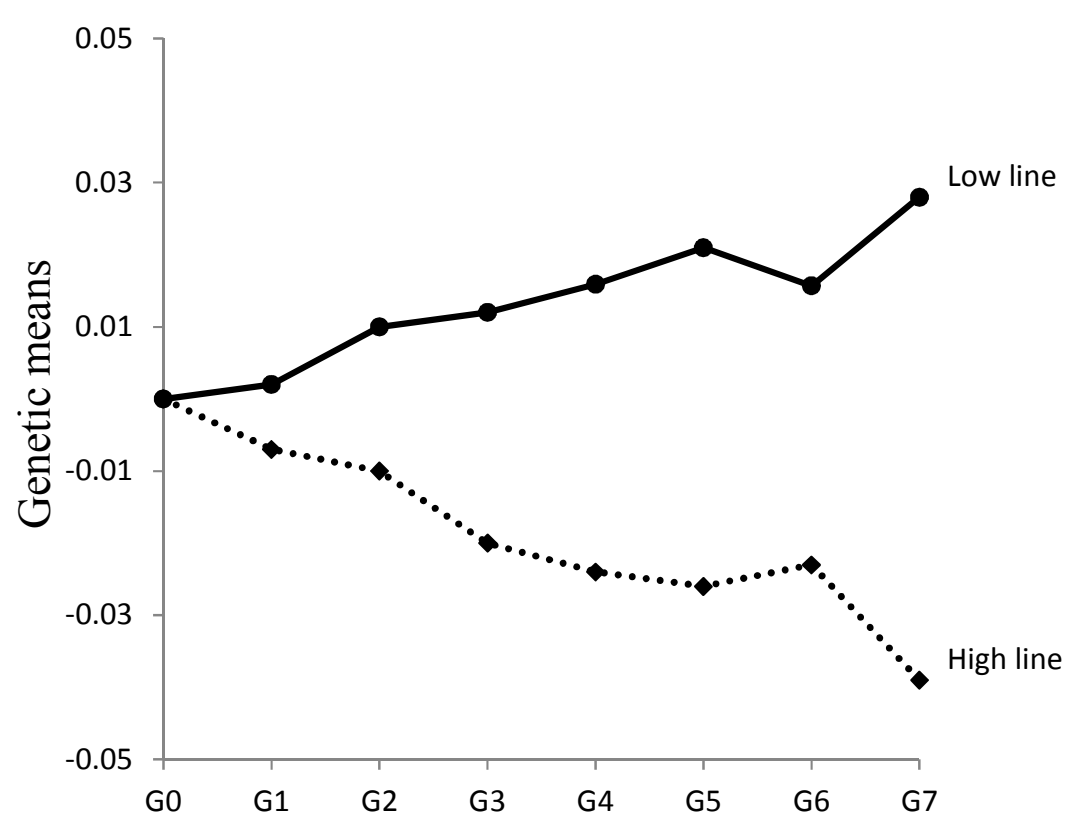

2. a) Correlated response to selection in embryonic survival 


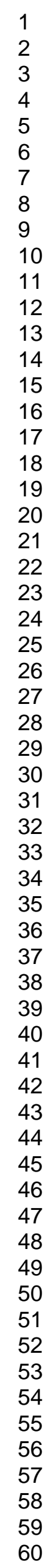

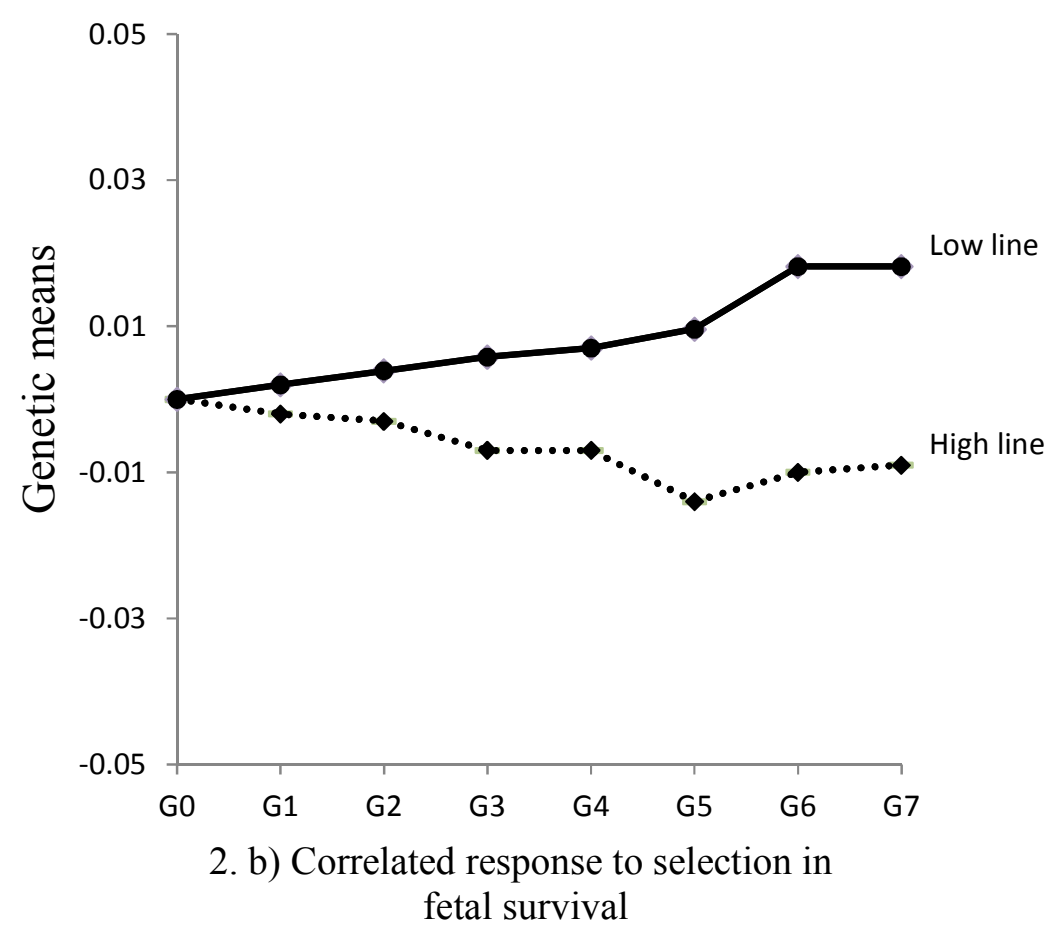


1

2

3

4

5

6

7

8

9

10

11

12

13

14

15

16

17

18

19

20

21

22

23

24

25

26

27

28

29

30

31

32

33

34

35

36

37

38

39

40

41

42

43

44

45

46

47

48

49

50

51

52

53

54

55

56

57

58

59

60

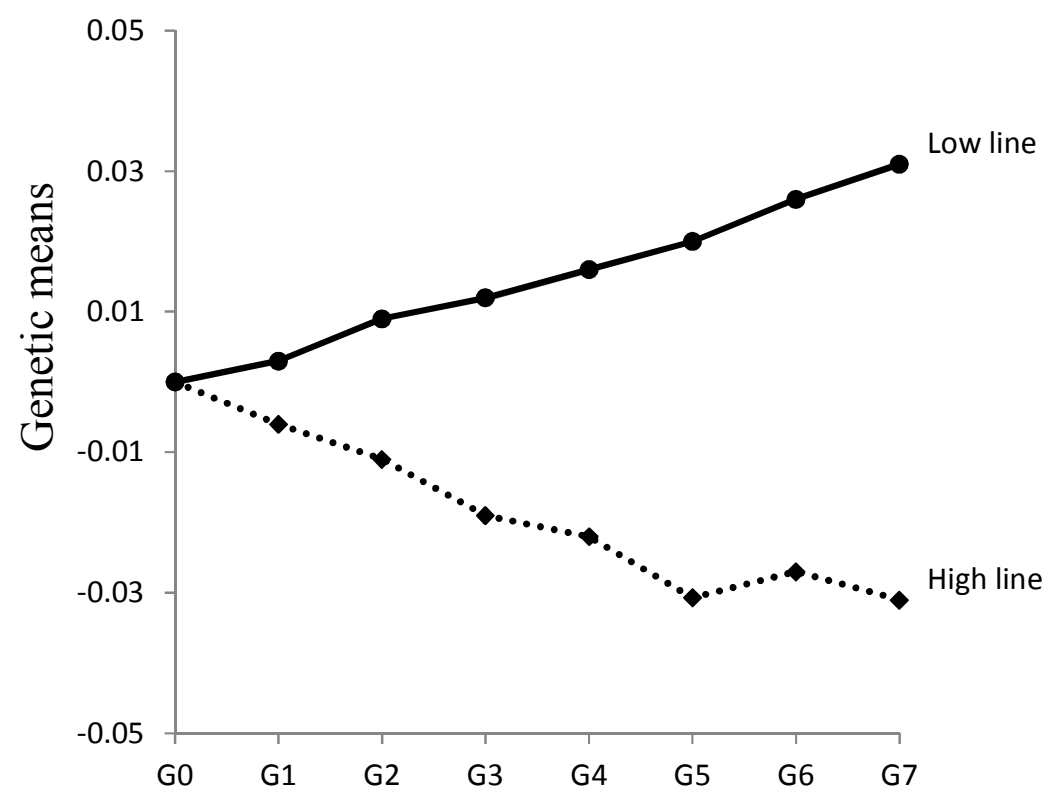

2. c) Correlated response to selection in prenatal survival 